Acta Hispanica (2015) 20: 7-19

\title{
LA METÁFORA DEL VIAJE EN UN VIAJE DE NOVIOS DE EMILIA PARDO BAZÁN
}

\author{
ANTOINE Bouba KIDAKOU
}

Université de Maroua (Cameroun)

Resumen: Dentro del inmenso corpus de la narrativa española del siglo XIX se particulariza la novela de Emilia Pardo Bazán, Un viaje de novios, por el estilo particular adoptado y una concepción del viaje como alegoría. En la obra la autora se aleja de la concepción tradicional del viaje y de las modalidades de su escritura, utilizando los apuntes de un viaje que ha realizado para escribir una novela donde el valor científico-formativo es el aspecto más importante. Pardo Bazán explora el aspecto trascendental del viaje $y$, en este trabajo pretendemos analizar las diferentes técnicas utilizadas por la escritora para su metaforización. El viaje viene a considerarse como un recorrido en el que el desplazamiento geográfico se acompaña o se convierte totalmente en movimiento interior. Las diferentes etapas del viaje físico realizado conforme al itinerario seguido muestran una progresiva transformación subjetiva de la protagonista de la obra y se convierten en etapas claves de un viaje metafórico bajo cuya perspectiva se realiza el presente estudio.

Palabras clave: viaje, metáfora, transformación mental

\begin{abstract}
Within the vast corpus of the nineteenth century Spanish narrative, Emilia Pardo Bazán's Un viaje de novio, deserve a different consideration due to a particular style adopted by the author and the consideration of travel as an allegory of life. The author departs, hence fore, from the way how travel was understood in the nineteenth century when writers based their travel writings or novels on the scientific and educational aspects. Pardo Bazan explores the transcendental aspect of travel fact and this paper studies the different techniques used by the writer to develop the metaphor of travel considering the geographical movement as an internal trip. The subjective and progressive transformation of the main protagonist, according to the itinerary of the trip, is studied as that internal journey.
\end{abstract}

Key words: travel, metaphor, mental transformation

\section{Introducción}

Al empezar este estudio, nos parece importante señalar unos cuantos rasgos característicos de la producción de Emilia Pardo Bazán y apuntar su interés por el tema del viaje. Más conocida como escritora naturalista con una inmensa producción 
novelística, poética, ensayística y crítica, Emilia Pardo Bazán es a la par un poco desconocida como viajera apasionada que se interesa por el tema del viaje desde varias perspectivas en sus obras. Esa pasión de doña Pardo Bazán por los viajes ha sido reconocida por críticos que se interesaron por este aspecto de su obra, como se puede advertir en el siguiente comentario de un estudioso de la literatura de viajes: "Dentro do ámbito europeo, España, como país 'exótico', é un dos ámbitos preferidos para o viaxeiro romántico e posromántico, de modo que nas letras decimonónicas abundan as viaxes por España de autores franceses, ingleses, alemáns, rusos... Pero tamén -aínda que poucos e xa na segunda metade da centuria- hai españois que viaxan, pola terra patria ou alén das súas fronteiras, e deixan testemuño escrito das súas andanzas e impresións; entre eles destaca de xeito moi notable Emilia Pardo Bazán (1851-1921).”"1

En el mismo sentido escribe Freire López, uno de los mejores especialistas en la obra de Emilia Pardo Bazán, lo siguiente: "Emilia Pardo Bazán se interesó por la literatura de viajes, hasta el punto de que ya en una de sus tempranas estancias en París dedicó bastantes horas en la Biblioteca Nacional a un estudio que confiesa que fue de los que más le entretuvieron y que consistió en «registrar libros de viajes de los siglos XVII y XVIII»... Pero una cosa es ser entusiasta de los viajes y otra contárselos a los demás, y en el caso de doña Emilia vemos que guardó para sí misma las notas que en ellos hubiera tomado y que no publicó ninguna obra de viajes hasta que encontró la razón y el cauce para hacerlo en el género periodístico de la crónica, porque como crónicas en la prensa nacieron sus libros Mi romería, Al pie de la torre Eiffel, Por Francia y por Alemania, Por la España pintoresca, Cuarenta días en la Exposición y Por la Europa católica."2

Muestra de esa pasión por los viajes y la literatura de viajes es el importante número de relatos de viajes que nos ha legado la escritora, de los que destacan con mucha relevancia De mi tierra, 1888; Mi romería, 1888; Al pie de la Torre Eiffel, 1889; Por Francia y por Alemania, 1889; Por la España pintoresca, 1896; Cuarenta dias en la Exposición, 1901; Por la Europa católica, 1902; Notas de un viaje por la Italia del Norte, 1902.

Sin embargo, y aunque el viaje es el elemento principal sobre el que se construye la obra, Un viaje de novios, objeto del presente estudio y una de las primeras obras de la autora sobre el tema, es una novela en la que explora el viaje desde una perspectiva distinta al tratamiento del viaje según el canon de la escritura de los relatos de viajes, estilo que adopta más tarde adopta en los relatos de viajes ya señalado.

$\mathrm{El}$ aspecto específico de esta novela que nos interesa más es el viaje en su sentido filosófico, en cuanto que forma parte de las experiencias existenciales del ser humano, de las que suele ser una de las metáforas predilectas. ${ }^{3}$ Postulamos, desde luego, como

${ }^{1}$ José Manuel GONZÁLEZ HERRÁN, “Andanzas e visións de doña Emilia (a literatura de viaxes de Pardo Bazán)", in: Revista Galega do Ensino, 27 (maio 2000), 37.

2 Ana María FREIRE LÓPEZ, "Los libros de viajes de Emilia Pardo Bazán", in: García Castañeda, Salvador (Coord.), Literatura de viajes. El viejo Mundo y el Nuevo, Madrid, Castalia, 1999, 204-205.

3 Jacques LAJARRIGE, “Avant-propos”, in: Austriaca, 60, junio de 2006, 7. 
hipótesis básicas, que Un viaje de novios, sin ser precisamente un relato de viajes, tiene una estructura conforme a los criterios de escritura de esos relatos; que en su funcionamiento textual, físico, psicológico y su implementación espacial a lo largo del recorrido, el viaje funciona como símbolo; esto es, un tropo o una alegoría de las andaduras de la vida humana. Antes de abordar el análisis específico de esa meteorización de la vida, nos parece importante señalar algunas similitudes entre esta obra y los relatos de viajes para ver claramente las técnicas de los relatos utilizadas por la autora para escribir esta novela.

\section{Elementos pertinentes del género viático en Un viaje de novios}

En este apartado, pretendemos ilustrar los rasgos pertinentes que comparte esta novela con los relatos de viajes y que le confieren su estatuto de novela (o libro o relato) de viaje según nos conformamos con los criterios de definición de este corpus propuestos por Rosca ${ }^{4}$, Popeanga ${ }^{5}$ o Belenguer Jané ${ }^{\text {, por }}$ citar unos casos. Estos criterios son, en todo caso, los siguientes.

\subsection{El itinerario}

Pérez Priego, considerado como uno de los primeros críticos en sentar las bases teóricas del estudio literario de la literatura de viajes desde una serie de criterios en el siglo XX, considera el itinerario como uno de los elementos clave, tal vez fundacionales, de estos relatos. "Atendiendo a su orden constructivo, lo primero que puede observarse es que en el libro de viajes la narración se articula básicamente sobre el trazado y recorrido de un itinerario, el cual constituye la urdimbre o armazón del relato, de modo semejante, por ejemplo, a la sucesión de reinados o el sistema de anales en el género cronístico.”

Un viaje de novios es una obra construida respecto al trazado de un itinerario que empieza en León (España). "Mientras el acompañamiento desfilaba, con lentitud de duelo, por las calles mal empedradas de León, el tren corría, dejando atrás las interminables alamedas de chopos que parecen un pentagrama donde fuesen las notas verde claro, sobre el crudo tono rojizo de las llanadas."

\footnotetext{
${ }^{4}$ Angela ROSCA, La tipología de los discursos en los libros de viajes de Nibai Tican Rumano, Madrid, Universidad Complutense (Tesis Doctoral), 2006.

${ }^{5}$ Eugenia POPEANGA CHELARU, "Lectura e investigación de los libros de viajes medievales", in: Revista de Filología Románica, 1991, Anejo I, Madrid, Universidad Complutense, 9-27.

${ }^{6}$ Mariano BELENGUER JANÉ, Periodismo de viajes, Sevilla, Comunicación Social, 2002.

7 Miguel Ángel PÉREZ PRIEGO, "Estudio literario de los libros de viajes medievales", in: Epos, Revista de Filología, Madrid, UNED, 1984, 220.

${ }^{8}$ Emilia PARDO BAZÁN, Un viaje de novios, Luarna (edición electrónica), 2013, 31.
} 
El viaje finaliza en Francia (París), después de señalar las principales etapas del recorrido: Venta de Baños, Miranda de Ebro, Vitoria, Alsasua, Irún, Hendaya, Bayona y Vichy. Desde el destino final, se anuncia el regreso al punto de partida. "El hace sus maletas para tomar el tren de la noche... Se va a Madrid." 9

\subsection{La combinación de la descripción y la narración}

Los fragmentos descriptivos, que constituyen uno de los aspectos de suma importancia en la literatura de viajes ${ }^{10}$ se combinan hábilmente con las narraciones para presentar el relato como un tejido armonioso de la historia contada. En la novela de Pardo Bazán se nota que la historia tiene un desarrollo único y lineal, mediante la técnica combinada de la repetitio, la digressio y la abreviatio, con una casi ausencia de entrelazamientos de acciones paralelas. La obra consiste en una pura narración lineal y continuada.

\subsection{La descripción de las peripecias según el orden cronológico}

Sobre este aspecto, dice Pérez Priego lo siguiente. "En el trazado de ese itinerario el narrador se ve obligado a adoptar también un orden cronológico - el tiempo que dura el recorrido- - con el fin de dar cuenta, más o menos puntual, del desarrollo y de la historia del viaje."11

Según este criterio, la presentación o descripción de las realidades observadas a lo largo del itinerario seguido por el viajero-narrador se ciñe al trazado del recorrido, marcando así la dependencia del desarrollo de la historia del viaje al marco cronológico estricto. En Un viaje de novios, la linealidad de la cronología del relato se ve impuesta por la progresión de los viajeros en el espacio. El relato se ajusta perfectamente a los criterios de un diario, es decir "una crónica cotidiana de los sucesos y escenarios del viaje". ${ }^{12}$

\subsection{La realización de un viaje}

Tanto en los textos factuales (relatos de viajes) como en los ficcionales (novelas de viajes) el viaje actúa como hilo conductor y condicionante del relato. Cabe señalar que Alburquerque García recoge bajo el marbete de literatura de viajes todas las "obras en las que el viaje forma parte del tema o en las que actúa como motivo literario". ${ }^{13}$ En Un viaje de novios el viaje condiciona el relato, como queda dicho, y esta obra encaja, desde luego, en este corpus genérico de literatura de viajes.

\footnotetext{
${ }^{9}$ Ibidem, 500 .

10 Sobre el tema véase Román ORTEGA, "La descripción en el relato de viajes: los tópicos", in: Revista de Filologia Romanica, Anejo IV, 2006, Madrid, Universidad Complutense, 224; Sofía CARRIZO RUEDA, Poética del relato de viajes, Kassel, Reichenberger, 1997, 17; PÉREZ PRIEGO, op. cit., 232.

${ }^{11}$ Ibidem, 223.

12 Ibidem, 224.

${ }^{13}$ Luis ALBURQUERQUE GARCÍA, "El relato de viajes: hitos y formas en la evolución del género", in: Revista de Literatura, 145, Madrid, 2011, 18.
}

10 | Acta Hispanica, Hungría 20: 7-19, 2015, ISSN: 1416-7263 
La ausencia de los «Mirabilia», otro elemento esencial que cita Pérez Priego como constante en la literatura de viajes en general, es muy llamativa en Un viaje de novios. Los aspectos fabulosos o extravagantes de los libros de viajes, casi siempre relacionados con la descripción de tierras lejanas o poco conocidas, consisten en la presentación de hechos o realidades descomunales dignas de ser señaladas al público lector, como se puede notar en este comentario de Bouba Kidakou: “...uno de los constantes geográficos de los libros de viajes desde la Edad Media es la evocación de espacios extraños que consisten en territorios de lo maravilloso expresado desde varios puntos de vista pero con rasgos de fábula: lo maravilloso en el sentido positivo (riquezas fabulosas en oro, pedrerías preciosas y especias de todo tipo, razas humanas que gozan de una longevidad increíble o que llevan una vida purísima y que se gobiernan por leyes irreprochables, o que tienen una religión única como en el caso del imperio del Preste Juan...) y en el sentido negativo (abundancia vegetal lujuriante y fauna de gran tamaño, licencias sexuales extravagantes y fuera del común, desnudez corporal con descubrimiento de formas físicas y hábitos alimenticios extraños por lo repelente, monstruos humanos y animales y espacios estructurados como paradigmas infernales...)."14

No obstante la evolución de los contenidos de la literatura de viajes, persisten todavía elementos fabulosos en muchos de ellos. Muestra de ello nos la ofrecen la obra de Niguel Barley El antropólogo inocente (1983), una novela de viajes escrita sobre las realidades socioculturales del norte de Camerún en la África negra, o varias obras del viajero español Javier Reverte entre las que destacan su novela La canción de Mbama (2007) sobre las realidades de Guinea Ecuatorial, y sus relatos El sueño de África (1996), Vagabundo en África (2003) o Los caminos perdidos de Africa (2002), que describen las realidades de varios países de África. Lo mismo puede notarse en el relato de Raúl Guerra Garrido Viaje a una provincia interior, o en el de Julio Llamazares El río del olvido (1990).

La ausencia de lo maravilloso no resta importancia a la calidad de la obra de Pardo Bazán en cuanto a su estatuto como novela de viaje; más bien se ajusta a una nueva norma de la escritura del viaje adoptada desde el siglo XVIII por los escritores-viajeros. Zigmunt comenta esa poética de la literatura de viajes en los términos que siguen. "La época de la Ilustración también supuso un cambio en la forma de entender el viaje, cuyos motivos se volvieron más complicados. Conforme con el nuevo espíritu, cualquier desplazamiento debería caracterizarse por su valor educativo. En primer lugar, cabe mencionar las expediciones científicas en las cuales el conocimiento y la investigación eran el motivo del viaje y el objetivo en sí mismo.”15

\footnotetext{
${ }_{14}$ Antoine BOUBA KIDAKOU, África negra en los libros de viajes españoles de los siglos XVI y XVII, Madrid, Editorial Académica Española, 2012, 136.

${ }^{15}$ Karolina ZYGMUNT, "La construcción de la experiencia del viaje en la escritura : figuras del escritor viajero contemporáneo", in: Kamchatka, 2, diciembre de 2013, 109.
} 
Esa forma de entender el viaje en la Ilustración, y que se prolonga en el siglo XIX en gran medida, transforma el desplazamiento espacial en una fuente de conocimiento, marcando así una diferencia con las épocas anteriores en las que el viaje se realizaba para cumplir con una obligación (viajes de embajadores, misioneros, exploradores y de campañas militares) o por motivaciones materialistas (viajes de mercaderes, conquistadores o colonizadores).

Después de estas precisiones sobre el estatuto de Un viaje de novios como novela de viajes, es preciso volcar la atención al aspecto específico que es el objeto de este trabajo: el viaje, no solo como elemento estructurador de todo el relato (aspecto ya atendido por Bühlam $)^{16}$ sino como realidad alegórica, considerando el hecho de viajar como itinerantica vital con todas sus proyecciones, sus efectos transformadores en los protagonistas. Según Barrio Marco "La vida y la muerte han sido alegóricamente comparadas y descritas desde antiguo por medio de la metáfora del viaje, puesto que un viaje indica pasaje, tránsito, cambio e intercambio de espacios, vivencias y experiencias físicas y espirituales." 17 Si partimos de este postulado del poder transformativo del viaje en el hombre, el acto de viajar se convierte en una experiencia trascendental. Las diferentes etapas de la transformación de la protagonista que nos interesa en este trabajo, Lucía González, y la naturaleza de los cambios producidos en el personaje son los aspectos específicos que se analizan a continuación.

\section{La transformación de Lucía por el viaje}

En este apartado nos interesamos por cómo, a través de los diferentes hitos que constituyen las etapas del itinerario, se realiza la transformación subjetiva de la protagonista y en qué formas se construye esa transformación.

\subsection{Lucía al inicio del viaje}

Al iniciar el viaje en León, se presenta a la protagonista como una joven de dieciocho años con rasgos infantiles. "Vio Lucía sin disgusto al cortés y afable Miranda, y reparó con pueril curiosidad el aseo de su persona...Traía a la niña diariamente alguna baratija, para ella desconocida hasta entonces... Acertó éste a ponerse al nivel de conversación de Lucía, y mostróse muy enterado de las cosas femeniles, infantiles dijera mejor; y llegó el caso de que la niña le consultase acerca de su peinado, de sus trajes..."18

16 Regula BÜHLMANN, "Un viaje de novios ¿una novela de viajes?”, in: J. M. González Herrán, C. Patiño Eirin, E. Penas Varela (editores), La literatura de Emilia Pardo Bazán, A Coruña, Fundación Caixa Galicia, 2009, 209-216.

${ }^{17} \mathrm{~J}$. M. BARRIO MARCO, "El viaje Arquetípico-iniciático: El viaje como génesis y arquetipo cultural de la Literatura Norteamericana", in : F. Manuel MARIÑO y OLIVA HERRER,(eds), El viaje en la literatura Occidental, Valladolid, Secretaria de publicaciones UVA, 2004, 180.

${ }^{18}$ PARDO BAZÁN, op. cit., 68. 
El vocablo más utilizado en la obra para referirse a Lucía en las primeras etapas del viaje es «niña», con toda su carga semántica y sus implicaciones psicológicas. Lucía, como niña, al casarse con Aurelio Mirando, poco entendía del matrimonio y del amor. Aunque no se casó contra su voluntad, tampoco lo hizo por amor. "Sin un sonrojo, sin perder minuto de sueño, sin que el latir del corazón se le acelerase cuando Miranda, desahogado siempre, repicaba la campanilla o entraba haciendo ruido con las flamantes botas. Como ningún amoroso requiebro de Miranda vino a confirmar los dichos de las gentes, estaba Lucía descuidada y tranquila lo mismo que de costumbre."19

La pareja nunca se trata con cariño, ni con pasión amorosa, por falta de correspondencia de ella: la distancia es lo que caracteriza sus relaciones, hasta tal punto que Lucía llama a su marido "el señor de Miranda". ${ }^{20}$ Esta distancia psicológica, es la que reforzará y empeorará la distancia física cuando la ausencia de Aurelio Miranda obliga a Lucía a viajar hasta Bayona sola. ${ }^{21}$ Es precisamente durante estas etapas del viaje, durante la ausencia del marido, cuando Lucía experimenta el proceso de transformación en el que adquiere otra personalidad. Pero antes de analizar este proceso transformacional de la personalidad de Lucía, señalemos un dato que puede barajarse como un indicio de la incompatibilidad entre los desposados, desde el principio del viaje y que dará sus retoños al final del recorrido en términos de ruptura: la incomprensión y la ausencia de correspondencia. Los desposados no tienen la misma concepción del viaje que estaban realizando. Para Aurelio Miranda, se trata de un viaje de novios, para ir a pasar la luna de miel con su joven esposa: de ahí la elección de Francia como destino. Además, Miranda se propone aprovechar su estancia en Vichy para curar sus achaques hepáticos.

Lucía, en cambio, no lo tiene claro desde el principio: tiene simplemente ganas de viajar; primero a Vichy conforme al deseo de su esposo, pero luego, cuando irrumpe Artegui en su vida por casualidad, se anima por París. Esa indecisión y esa fluctuación anímica, son elementos que ilustran la falta de madurez en la personalidad de Lucía.

\subsection{El proceso de transformación}

En el transcurso del viaje, Lucía va adquiriendo madurez y va cambiando; empezando a transformarse mediante las experiencias acumuladas en el recorrido del itinerario.

\subsubsection{La transformación física}

Presentada como un ser tierno, con cuerpo infantil al principio, Lucía va transformándose físicamente a medida que avanza en el espacio y en el tiempo. En una de las etapas del viaje, Miranda nota esta transformación en su esposa: "Miranda se reía,

\footnotetext{
${ }^{19}$ Ibidem, 69-70.

${ }^{20}$ Ibidem, 89 y passim

${ }^{21}$ Aurelio Miranda había bajado del tren en Venta de Baños para recuperar unas pertenencias olvidadas en el restaurante donde cenaron, y cuando sale del restaurante el tren estaba iniciando la marcha.
} 
sentado próximo a su novia, mirándola de cerca y hallándola muy linda, transformada casi con el tocado de viaje y la animación que encendía sus mejillas y arrebolaba su fresca tez"'.22

Desde esta etapa, los gestos, los movimientos y los ademanes de Lucía van adquiriendo las características de una persona físicamente madura. Sin embargo, los detalles sobre los cambios morales y psicológicos son los que abundan en la obra.

\subsubsection{La transformación moral}

Lucía es una persona que se deja proteger cuidadosamente por su esposo Miranda al principio del viaje, asumiendo así, aunque inconscientemente, el tradicional papel de esposa sumisa: "Lucía, hay que subirse: el tren andará en seguida... Y con ademán cortés y discreto, ayudó a la novia a subir, empujándola levemente por la talla". ${ }^{23}$ Durante el trayecto de León a Venta, Miranda concentra toda su atención en vigilar y cuidar de Lucía, ofreciéndole todo cuanto necesita para estar cómoda: comida, bebida, afecto etc. Ella se deja atender plácidamente y guidada más bien por la inocencia que por el consentimiento.

Desde Venta hasta Bayona, Lucía viaja sin Miranda, sin protector. Y es precisamente en este tramo cuando se produce la mayor transformación del personaje. El primer factor de esta transformación es, pues, la ausencia de su marido. Ante esta ausencia de protección Lucía se ve expuesta a peligros y debe resistir a cualquier intento de avasallamiento o de agresión. Esta primera lección de vida la lleva a madurar en sus comportamientos y en sus discursos. Al entrar en contacto con Artegui en los primeros momentos de la ausencia de su marido, Lucía está todavía bajo la influencia psicológica del proteccionismo que le había inculcado éste y considera a Artegui como su nuevo protector. En este sentido, le dice: “¿Qué sería de mí si no le hubiese encontrado tan a tiempo?"24 Poco a poco, Lucía aprende a ganar su independencia, prescindiendo de la protección de Artegui. También se considera como interlocutora en las conversaciones que mantiene tanto con Artegui como con Gonzalo y los demás pasajeros del tren. Pueden apreciarse estos discursos suyos, en conversaciones con Artegui, como muestra de su maduración.

“-No, señor- declaró Lucía ofendida-; le entiendo a usted muy bien, y en prueba de ello voy a adivinar eso que se calló. ¡Verá usted que sí!-gritó, cuando Artegui hubo meneado sonriendo la caneza-. Usted se aburrió menos en esa temporada en que fue médico de afición; pero en cambio...con ver tanto muerto y tanta sangre, y tanta barbaridad, aún se volvió usted más...más judío que antes." 25

La firmeza y la seguridad que trasparecen en los propósitos de Lucía traducen perfectamente esta maduración del personaje. Artegui es, por cierto, un agente

\footnotetext{
22 Ibidem, 86.

${ }^{23}$ Ibidem, 25.

${ }^{24}$ Ibidem, 174.

${ }^{25}$ Ibidem, 218-219.
} 
encadenante de este proceso pero, al mismo tiempo, la primera víctima del mismo. Durante la estancia del grupo en Bayona hasta la llegada de Miranda, las relaciones entre Artegui y Lucía se reducen a unas conversaciones en las que se percibe una dialéctica, en un trasfondo de moralización, de aleccionamiento y de descubrimiento.

Hacia el final de la obra Lucía alcanza una gran madurez, no sólo en sus discursos sino también en sus acciones. Ante la gravedad de la enfermedad de Pilar, ella es quién toma la iniciativa de las acciones para ayudar a la enferma a recuperarse. "La única persona que se consagró a que Pilar observase el régimen saludable fue, pues, Lucía". ${ }^{26}$ En Vichy, Lucía vive más entregada a cuidar de Pilar que a su obligación matrimonial, al lado de su marido. Entre quejas y reproches dice Miranda a Lucía: "No parece sino que esa chica es la única que tiene aquí que cuidarse. También los demás padecemos y hemos de observar régimen. Hoy justamente estoy fatal..."27 Pero Lucía, como respuesta a esa amonestación, le vuelve la espalda a Miranda y se aleja. Poco a poco Lucía, valiéndose de la fuerza que le propicia ese proceso de maduración y de transformación, adquiere más independencia y libertad. Llega a dar órdenes a su marido y a negarse a cumplir con su obligación conyugal. ${ }^{28}$

El descubrimiento del amor es otro factor desencadenante de la transformación de Lucía. Antes de conocer a Ignacio Artegui, Lucía tenía una idea confusa del amor, ya que lo que la une a Miranda no es un sentimiento amoroso, sino más bien una convención social. Dice la joven muchacha a este propósito: “¿Qué entiendo yo de bodas, ni de...?”29 Gracias a Artegui, descubre Lucía el amor (aunque todavía no es consciente de ello hasta que vuelvan a encontrarse en París más tarde). A pesar de algunos desacuerdos en ciertos temas específicos como la religión, y en ciertos valores sociales (el sentido del matrimonio, por ejemplo), las relaciones entre Artegui y Lucía se caracterizan por una perfecta comprensión empática, una interacción positiva y un enriquecimiento mutuo. Muchos fragmentos en la obra denotan la simbiosis, casi una telepatía entre los dos personajes, hasta tal punto que se creen enamorados uno del otro.

En París, Lucía siente un obsesivo anhelo de volver a encontrarse con Artegui y lleva su proyecto a la realidad cuando por fin, irrumpe en la casa de éste. La descripción del reencuentro entre los dos es similar a una escena de reencuentro entre dos enamorados que hubieran sido separados fortuitamente con la intensidad en las emociones, tensiones y distensiones, pero otra vez más sólo el peso de la convención social detiene las pasiones desatadas de los dos amantes. ${ }^{30}$

\footnotetext{
${ }^{26}$ Ibidem, 285.

${ }^{27}$ Ibidem, 362.

${ }^{28}$ Véase las páginas 361-362 y 317.

${ }^{29} \mathrm{Ibidem}, 79$.

${ }^{30}$ Véase las páginas 465-487.
} 
La metáfora del viaje en un viaje de novios de Emilia Pardo Bazán

\section{E1 desenlace: un retorno solitario}

Al término del recorrido y de las peregrinaciones de los desposados (Lucía y Miranda), nos encontramos con una pareja moral y físicamente rota y separada. Entre decepción, desilusión y enfado, Aurelio Miranda decide acortar su estancia en Francia para regresar a España tras descubrir que su esposa se siente atraída por Artegui a quien Lucía visita en su casa. Miranda hace reprobaciones violentas a su esposa ante lo que llama la infidelidad pero Lucía prefiere no ofrecerle ninguna explicación sobre su visita a Artegui. Al contrario, se indigna y lo único que anhela es reunirse con su amante para hallar la paz interior y la felicidad. “...Ardían los cirios ante Pilar, y en la fachada de Artegui se veía la luz a través de unas cortinas... Bajar diez escalones, y encontrarse en el jardín; atravesar el jardín, y encontrarse sobre un pecho amante que para ella era cera suavísima, acero para sus enemigos..."31

El proceso evolutivo de la mentalidad y de los sentimientos es tan gradual, lógico y evidente que no sorprende a nadie que Lucía se niegue a permanecer al lado de su marido y a seguirle en su viaje de regreso a España. Puede apreciarse esta conversación suya con el padre Arriogoita al respecto:

“-Él hace sus maletas para tomar el tren de la noche... se va a Madrid...La deja a su usted... Si usted quisiera arrojarse a sus pies, y con humildad y arrepentimiento...

-Eso no, padre,- gritó la altiva castellana. Creerá que soy lo que él llama... No, no."32

Lucía regresa a España sola, y completamente transformada. "Más de dos semanas dio pasto a las lenguas ociosas de León el singular suceso de la llegada de Lucía González, sola, triste, desmejorada y encinta, a la casa paterna." 33

El viaje de Lucía se convierte en una metáfora a partir de este retorno, y de los cambios observados en el personaje a su regreso. La primera observación es que, con el regreso de los protagonistas, el viaje se presenta como una realidad cíclica. Empieza en León como punto de inicio y regresa a León como punto de regreso. Se trata de un ciclo completo, como el de una vida humana. Y precisamente a partir de este elemento, el viaje de Lucia puede interpretarse como la metáfora de la andadura mental de la protagonista. El desplazamiento físico de Lucía González se convierte en un viaje interior: la auto-reflexión o introspección que hace para aclarar cuestionamientos u otros conflictos existenciales consigo misma y con su entorno. Este desplazamiento adquiere, en el mismo contexto, un aislamiento que ayuda en el esclarecimiento de las ideas y facilita la toma de consciencia y de decisiones con toda libertad. En el mismo sentido, el viaje realizado por Lucía es un medio de conocimiento: en el transcurso de ese viaje el personaje realiza una acumulación de lecciones, una adquisición de sabiduría gracias a las relaciones con el espacio, el tiempo y el otro. De acuerdo con Boliñas

\footnotetext{
${ }^{31}$ Ibidem, 497.

${ }^{32}$ Ibidem, 501.

${ }^{33}$ Ibidem, 502.
}

16 | Acta Hispanica, Hungría 20: 7-19, 2015, ISSN: 1416-7263 
Fernández "Retornar, regresar, implica un marco semántico o cuadro de sentido que incluye espacio, dentro/fuera, movimientos de ida y vuelta, disolucion en lo exterior, interiorización, etc." 34 El progreso de Lucia en el espacio es también un proceso mental y, de resultas, moral. El cambio se produce tanto en su cuerpo como en su intimidad personal. Al final, Lucia vuelve (retorna) al espacio inicial desde el que se inicia el viaje, pero ya presenta rasgos diferentes de su personalidad: está deshecha y poco reconocible, y sus aspectos físicos y morales llevan a percibir el viaje como una alegoría del proceso natural de decadencia (fisica y moral). El retomo de la protagonista puede interpretarse como un intento de reencuentro con su personalidad de origen, un intento de reversión para volver al estado propio.

Una perspectiva adicional del acercamiento metafórico al concepto de viaje descrito en este relato nos remite al tren en su simbolismo asociado al viaje en el siglo XIX. Este poderoso emblema mecánico se consideraba en general como "heraldo de civilización" 35 , pues suscitaba el entusiasmo y la admiración por su poder abolicionista del tiempo y del espacio, por su papel unificador e integrador, y por la revolución que supone. Sin embargo, en Un viaje de novios el tren no se percibe desde este paradigma. El tren, en su curso, es percibido como la vida que fluye o como el diablo que se lleva el alma. Varias partes de la obra remiten a esa percepción. Muestra de ello se puede leer en uno de los fragmentos más significativos al respecto, en el que se puede ver el paralelismo insinuado entre el tren en su curso y la vida humana. "Fuera, los postes del telégrafo parecían una fila de espectros; los árboles sacudían su desmelenada cabeza, agitando ramas semejantes a brazos tendidos con desesperación pidiendo socorro; una casa surgía blanquecina, de tiempo en tiempo, aislada en el paisaje como monstruosa testa de granítica esfinge; todo confundido, vago, sin contornos, flotante y fugaz, a imitación de los torbellinos de humo de la máquina, que envolvían al tren cual envuelve a la presa el aliento de fuego de colérico dragón. Dentro del coche silencio religioso; dijérase que era un recinto encantado. El viajero corrió el transparente azul, cubriendo la lámpara; recostose en una esquina cerrados los ojos, y, estirando las piernas, las apoyó en el asiento fronterizo. Así pasaron estaciones y estaciones."36

Pardo Bazán se hace eco, en este sentido, de una importante opinión que desde el siglo XIX ve en tren en marcha un espectáculo sublime del fluir de la vida, de la fugacidad de la existencia humana asimilando las estaciones de partida, de paradas y de llegada del tren a las de la vida en su movimiento desde su inicio hasta la muerte. Esa asimilación del espectáculo sublime del fluir de la vida al del tren sigue animando todavía la escena literaria, pues se puede notar a finales del siglo XX, y a modo de ilustración, una propensión a ese paralelismo. En el prólogo de una significativa

${ }^{34}$ Carlos BOLIÑAS FERNANDEZ, "La metáfora platónica del retorno (reditio)", in: Revista Espñola de Filosofía Medieval, 10, 2003, 371.

${ }^{35}$ Lily LITVAK, "Abolición del tiempo y el espacio. El viaje en tren a fines del siglo XIX", in: Compás de Letras, 7, diciembre de 1995, 239.

36 PARDO BAZÁN, op. cit., 123. 
antología sobre el tren en la literatura, el escritor-viajero Julio Llamazares escribe en este sentido lo siguiente. "Desde el tren, la literatura redescubrió el paisaje... y confirmó la fugacidad, no sólo de los paisajes, sino de la propia vida. Cada estación, cada apeadero, cada cambio de agujas o de ritmo eran un canto a la modernidad, pero también la constatación de la vulnerabilidad de la vida y de la condición humana. Cada vagón de pasajeros o de carga resumía la historia y el destino de la humanidad. Y, así, poco a poco, al ritmo que los trenes y convirtiéndose ella misma en un tren de relatos y de estaciones de llegada o de partida..."37

En su estudio ya citado Lily Litvak apuntaba el papel del tren en la alegoría del viaje, recogiendo un comentario de Enrique Sepúlveda sobre el asunto: “...al ver el tren corriendo sobre los carriles de acero, «como alma que lleva Satán», nadie le quita de la cabeza el pensar que «aquello que rebulle dentro de la locomotora y brama y silba y lanza bocanadas de humo, chispas y llamas, es el mismísimo infierno, reducido por la divisibilidad, como acontece con la luz eléctrica, a un chorro simple de fuego amansado por las calderas y los tornillos del regulador de la máquina." 38

El tren, se ve, además de la alteración de las relaciones espaciales que provoca por la velocidad y de la aniquilación del espacio tradicional, viene a simbolizar el fluir de la vida humana en su recorrido terrenal hacia la muerte, pasando por varias alteraciones.

\section{Conclusiones}

La valoración final que se impone al término del análisis de Un viaje de novios puede formularse en tres dimensiones: en primer lugar, se nota que la obra encaja perfectamente dentro del corpus de novelas clasificadas en la categoría literatura de viajes, pues cumple la mayoría de los criterios definitorios del género.

En segundo lugar, la influencia de la época y del movimiento literario (Naturalismo) a los que pertenece la autora se manifiesta en el relato a través de las pormenorizadas descripciones de los paisajes y de las realidades sociales observadas por los viajeros a lo largo del trayecto de León a París. Sin embargo, y tal vez por ser una novela, la autora se distancia, en los largos fragmentos descriptivos de la obra, de las maravillas y del éxtasis de las contemplaciones de edificios, monumentos y otras realidades socioculturales que suelen caracterizar principalmente los relatos factuales. Esta postura de la autora caracterizada por una concepción del viaje como metáfora de la vida se une a otro aspecto del libro, el que advierte contra la fascinación de lo ajeno y de la modernidad, para hacer una diferencia en el tratamiento del tema del viaje en la literatura.

Por fin, la evolución de la personalidad de Lucía González, hasta la transformación total de su mentalidad en el transcurso del itinerario convierte asimismo el viaje realizado en una metáfora: las tres etapas del viaje (la salida, el recorrido del itinerario y la llegada a

\footnotetext{
37 Vidas sobre raíles: cuentos de trenes, Madrid, Páginas de Espuma, 2000, 7.

${ }^{38}$ LITVAK, op. cit., 240.
} 
destino) son etapas que corresponden a las del proceso de transformación mental de Lucía. Su salida de León marca su separación con su espacio de origen y con su entorno: es una ruptura con las asociaciones y vinculaciones con el espacio de origen. Esa ruptura provoca sufrimientos por el abandono de lo familiar, lo conocido pero también por el miedo a lo desconocido que se va a afrontar. La salida es pues, al mismo tiempo una ruptura y un inicio, el inicio de una nueva vida o de una nueva etapa en la vida. La segunda etapa, el recorrido del itinerario o el traslado, supone unos sufrimientos transformacionales por las presiones físicas y morales inherentes al desplazamiento físico que implican una evolución mental en la protagonista. La asimilación de los elementos que conforman las secuencias del itinerario y la incorporación de esos elementos en la personalidad de la protagonista tienen como consecuencia, en la tercera etapa, la llegada, la conversión del personaje inicial en otro distinto.

Estos aspectos de Un viaje de novios constituyen unas constantes en la mayoría de los libros que, según Carrizo Rueda “...irán adquiriendo un marcado carácter intimista pues serán las repercusiones del viaje en el mundo interior de quien lo realiza, los verdaderos núcleos del relato." 39

\footnotetext{
${ }^{39}$ Sofía CARRIZO RUEDA, "Morfología y variantes del relato de viajes", in: Carmona Fernández, F. y Martínez Pérez, A. (eds.) Libros de viajes, Murcia, Universidad de Murcia, 1996, 124.
} 